\title{
Studi Kasus Terhadap Peserta Didik yang Mengalami Perlakuan Bullying oleh Teman Sekelas
}

\author{
Maufur, Anna Septiyani Maullida \\ 1) Dosen Bimbingan dan Konseling FKIP UPS Tegal \\ 2) Mahasiswa Bimbingan dan Konseling FKIP UPS Tegal
}

Program Studi Bimbingan dan Konseling

FKIP - Universitas Pancasakti Tegal

\begin{abstract}
Abstrak
Rumusan masalah dalam penelitian ini adalah 1) Bagaimana kasus bullying yang mengakibatkan rasa tidak nyaman yang dialami korban pada peserta didik kelas X SMA Al-Irsyad kota Tegal tahun pelajaran 2014/2015?; 2) Apa penyebab dan dampak peserta didik kelas X SMA Al-Irsyad yang menjadi korban dari tindakan bullying oleh teman sekelas?; 3) Bagaimana upaya dan hasil penanganan terhadap peserta didik yang mengalami perlakuan bullying oleh teman sekelas di kelas X dengan layanan bimbingan konseling individu di SMA Al-Irsyad kota Tegal tahun pelajaran 2014/2015? Populasi di dalam penelitian ini adalah peserta didik kelas X SMA Al-Irsyad kota Tegal yang terlibat dalam kasus bullying yang berjumlah 12 anak, yang terbagi dalam 3 pelaku dan 9 korban. Pengambilan sampel menggunakan purposive sampling dan empat teknik pengumpulan data yaitu observasi, wawancara, dokumentasi, dan gabungan serta tiga teknik analisis data yaitu reduksi data, display data, mengambil simpulan dan verifikasi. Hasil penelitian menunjukan bahwa bullying terjadi di SMA Al-Irsyad kota Tegal. Terdapat tiga bentuk bullying (fisik, verbal, dan mental/psikologis) yang terjadi, mengakibatkan korban merasa tidak nyaman saat belajar di sekolah. Sebab pelaku melakukan bullying adanya faktor dari keluarga, teman sebaya, dan media video action. Untuk upaya penanganan dari kasus bullying guru BK melakukan konseling individu untuk melakukan klarifikasi kebenarannya kemudian dibuatlah surat pernyataan bagi pelaku untuk tidak mengulangi perbuatan bullying. Korban dan pelaku saling memaafkan dan korban merasa lebih baik dan tidak takut lagi.

Kata kunci: bullying, studi kasus, siswa
\end{abstract}

\begin{abstract}
Formulations of the problem in this research are; 1) How bullying case causes an uncomfortable feeling towards bullied students of grade X SMA Al-Irsyad Kota Tegal year 2014/2015; 2) What causes and impacts to get of bullied students; 3) How efforts and results of handling the bullied students by using individual counseling service applied in SMA Al-Irsyad Kota Tegal year 2014/2015. Population in this research is 12 students of grade X SMA Al-Irsyad Kota Tegal year 2014/2015. There are 3 bullies and 9 victims. Samples are taken by purposive sampling. In this research, the researcher uses observation, interview, documentation and three combination of data analysis techniques, they are: data reduction, data display, inference and verification.Result of the research shows that bullying case happens in SMA Al-Irsyad Kota Tegal. There are three kinds of bullying (physical, verbal and mental) happen which causing the victims feel uncomfortable to study at school. The motives used by the bullies are taken from family factors, friends, medias and videos. The effort to handle bullying case done by guidance and counseling teacher is by doing individual counseling to clarify truth. Afterwards, the bullies write a statement of not to repeat bullying act. At last, the victims and bullies forgive each other so that the victims feel more secured.
\end{abstract}

Keywords : bullying,case study, Students 


\section{PENDAHULUAN}

Penting sekali bagi orang tua untuk memahami bahwa bullying itu sama sekali bukan bagian normal dari masa kanak-kanak ataupun remaja yang harus dilewati. Karena bullying merupakan suatu problem yang harus diatasi. Tindakan bullying itu berakibat buruk bagi korban. Bahkan efeknya terkadang membekas sampai peserta didik telah menjadi dewasa.

Korban dari pelaku bullying akan merasa takut sampai yang terjadi adalah ketika korbannya adalah peserta didik, mereka malas untuk belajar, prestasi dalam belajar menurun, menyendiri, mengucilkan diri, depresi sampai akhirnya ingin pindah kelas hal itu merupakan akibat dari perilaku bullying. Upaya yang dilakukan guru di sekolah adalah adanya buku kasus yang terdiri dari level satu, level dua, dan level tiga, dengan begitu guru akan melakukan penangananya sesuai dengan tindakan yang di lakukan agar tidak semakin parah dalam kasusnya, kemudian peserta didik dimohon untuk melaporkan tindakan bullying kepada guru.

Sebuah perilaku menyimpang yang telah lama berlangsung dan mengancam segala aspek kehidupan sebagian besar anak-anak baik di lingkungan rumah, sekolah maupun di lingkungan maasyarakat adalah tindakan perilaku bullying. Banyak para ahli yang berpendapat mengenai bullying, ahli satu dengan ahli lain dalam mendefinisikan berbeda-beda, namun pada hakekatnya pengertian bullying tersebut adalah sama. Menurut Ken Rigby (Ariobimo Nusantara;2008;3)

Bullying adalah sebuah hasrat untuk menyakiti. Hasrat ini diperlihatkan ke dalam aksi, menyebabkan seseorang menderita. Aksi ini dilakukan secara langsung oleh seseorang atau kelompok yang lebih kuat, tidak bertanggung jawab, biasanya berulang, dan dilakukan oleh perasaan senang oleh pelaku bullying.

Bullying ada beberapa jenis dan wujudnya, menurut Coloroso dalam Gerakan Anti Bullying (2007) dalam hal ini praktik bullying yang terjadi di lingkungan sosial dapat dikelompokkan ke dalam tiga kategori : bullying fisik, verbal dan psikologis. Oleh karena itu diperlukan bantuan dari konselor sekolah atau guru pembimbing untuk mengatasi bullying. Dengan demikian karena keterbatasan kematangan peserta didik dalam mengenali dan memahami hambatan dan permasalahan yang dihadapi, maka konselor sebagai pihak yang berkompeten perlu memberikan intervensi. Upaya-upaya penanggulangan yang dapat dilakukan yaitu dengan memanfaatkan layanan bimbingan dan konseling. Salah satu bantuan yang dapat diberikan adalah dengan konseling pribadi yang menggunakan metode studi kasus (case study). Studi kasus akan mempermudah konselor sekolah untuk membantu memahami kondisi peserta didik seobyektif mungkin dan sangat mendalam.

\section{METODE}

Desain dalam penelitian kualitatif merupakan keseluruhan rencana untuk suatu kegiatan penelitian, termasuk empat ide utama : strategi, kerangka konseptual, tentang siapa atau apa yang diteliti, dan perangkat yang digunakan untuk mengumpulkan dan menganalisis bahan-bahan empiris. Desain menempatkan peneliti pada dunia nyata. Ketika permasalahan telah ditetapkan, desain berada diantara masalah penelitian dan data. Persoalan dalam desain adalah : data apa yang dibutuhkan, bagaimana dan dari siapa data tersebut akan dikumpulkan. Disini termasuk masalah strategi dan kerangka kajian. Suatu desain dalam penelitian ini adalah strategi menggunakan studi kasus serta layanan bimbingan konseling individual dengan sebuah peristiwa yang terjadi di sekolah yaitu adanya peserta didik yang mengalami perlakuan bullying oleh teman sekelas. Dengan mengumpulkan data dari berbagai informasi yang sudah ditentukan oleh peneliti. Susilo Rahardjo \& Gudnanto (2011:250) studi kasus adalah suatu metode untuk memahami individu yang dilakukan secara integrative dan komprehensif agar diperoleh pemahaman yang mendalam tentang individu tersebut beserta masalah yang dihadapinya dengan tujuan masalahnya dapat terselesaikan dan memperoleh perkembangan diri yang baik. 
HASIL

Tabel 1.

Faktor penyebab bullying siswa

\begin{tabular}{|c|c|c|c|}
\hline \multirow{2}{*}{ Faktor } & \multicolumn{3}{|c|}{ Pelaku } \\
\hline & AI & YA & MY \\
\hline Sekolah & 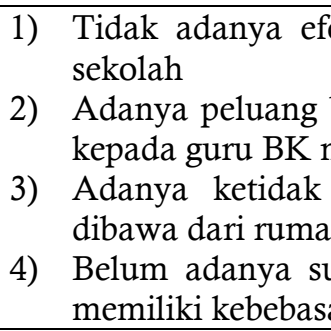 & $\begin{array}{l}\text { jera terhadap sanksi } \\
\text { agi pelaku karena korb } \\
\text { engenai masalah bullyi } \\
\text { elarasan terhadap ni } \\
\text { dengan yang diajarkan } \\
\text { ervisor didalam bus } \\
\text { didalam bus sekolah }\end{array}$ & $\begin{array}{l}\text { yang diberikan pihak } \\
\text { n tidak mau bercerita } \\
\text { g yang dihadapi } \\
\text { i dan budaya yang } \\
\text { disekolah } \\
\text { kolah, sehingga anak }\end{array}$ \\
\hline $\begin{array}{l}\text { Orang } \\
\text { Tua }\end{array}$ & $\begin{array}{l}\text { Ayahnya yang selalu } \\
\text { bersikap kasar } \\
\text { terhadap dirinya dan } \\
\text { sering } \\
\text { menggunakan } \\
\text { hukuman fisik serta } \\
\text { bentakan membuat } \\
\text { AI kesal, serta } \\
\text { marah. Hal tersebut } \\
\text { mengakibatkan } \\
\text { AI melampiaskan } \\
\text { segala bentuk } \\
\text { amarah dan } \\
\text { kekesalannya } \\
\text { terhadap } \\
\text { teman-temannya }\end{array}$ & & \\
\hline $\begin{array}{l}\text { Teman } \\
\text { Sebaya }\end{array}$ & & $\begin{array}{l}\text { Dalam hal ini, YA } \\
\text { merupakan korban. } \\
\text { YA kerap kali } \\
\text { dijauhi oleh } \\
\text { temantemannya } \\
\text { dan teman-temannya } \\
\text { selalu } \\
\text { memilih-milih teman } \\
\text { saat bermain. Saat } \\
\text { membuat kelompok } \\
\text { belajar pun YA } \\
\text { mengaku bahwa } \\
\text { temannya kerap kali } \\
\text { tidak mengajak } \\
\text { dirinya. Hal ini } \\
\text { membuat } \\
\text { YA merasa kesal dan } \\
\text { akhirnya mencoba } \\
\text { untuk melampiaskan } \\
\text { rasa kekesalannya } \\
\text { dengan melakukan } \\
\text { bullying terhadap } \\
\text { teman-temannya. }\end{array}$ & $\begin{array}{l}\text { MY mengaku bahwa } \\
\text { dirinya hanya } \\
\text { mengikuti apa } \\
\text { yang dilakukan } \\
\text { temannya. MY } \\
\text { mengatakan bahwa } \\
\text { ia } \\
\text { tidak ingin terlihat } \\
\text { aneh. Untuk itu } \\
\text { bullying yang } \\
\text { biasa dia lakukan } \\
\text { merupakan pengaruh } \\
\text { daro temanteman } \\
\text { sebayanya yang biasa } \\
\text { melakukan hal } \\
\text { demikian. }\end{array}$ \\
\hline Media & & & $\begin{array}{l}\text { Tontonan video } \\
\text { action perkelahian }\end{array}$ \\
\hline
\end{tabular}




\begin{tabular}{|c|c|c|c|}
\hline \multirow{2}{*}{ Faktor } & \multicolumn{3}{|c|}{ Pelaku } \\
\hline & AI & YA & MY \\
\hline & & & $\begin{array}{l}\text { yang disukai oleh } \\
\text { MY } \\
\text { menampilkan } \\
\text { banyak aksi } \\
\text { kekerasan } \\
\text { didalamnya. } \\
\text { Hal ini berpengaruh } \\
\text { terhadap MY, } \\
\text { dimana MY } \\
\text { belajar menjadi lebih } \\
\text { agresif dan kurang } \\
\text { empati } \\
\text { terhadap yang } \\
\text { lainnya }\end{array}$ \\
\hline
\end{tabular}

\section{PEMBAHASAN}

Berdasarkan hasil hasil observasi yang telah dilakukan di SMA Al-Irsyad Kota Tegal adanya kasus bullying yang dilakukan oleh peserta didik, kasus bullying yang terjadi masuk dalam tiga bentuk yaitu bullying fisik, bullying verbal, dan bullying mental/psikologis.

Dari hasil temuan dilapangan yang telah dilakukan dalam wawancara dan observasi, dimana faktor pendukung tersebut datang dari lingkungan sosial anak. Berdasarkan dengan temuan lapangan yang sudah didapat, diketahui bahwa ternyata faktor sosial yang mempengaruhi perilaku bullying tersebut muncul pada anak didapat dari pengaruh keluarga, teman sebaya, dan juga media (dalam hal ini video action perkelahian yang banyak menampilkan bentuk kekerasan fisik).

\section{SIMPULAN}

Berdasarkan hasil studi kasus yang telah dilakukan, diketahui bahwa bentuk bullying yang dilakukan oleh pelaku terdiri dari tiga jenis, yaitu bullying fisik, bullying verbal, dan bullying mental/psikologis. Dari ketiga pelaku, dua berjenis kelamin laki-laki dan satu berjenis perempuan. Beberapa bentuk bullying yang dilakukan mencubit, memukul, dan juga memaksa orang lain untuk mengerjakan tugas sekolah dan apa yang diinginkannya sehingga membuat korban merasa tidak nyaman.

\section{DAFTAR PUSTAKA}

Coloroso, Barbara. (2007). Stop Bullying (Memutus Rantai Kekerasan Anak dari Prasekolah Hingga $S M U)$. (alih bahasa : Santi Indra Astuti). Jakarta : PT. Ikrar Mandiri Abadi.

Nusantara, Ariobimo (Ed.). Suryatmini,Niken : asisten editor. 2008. Bullying : Mengatasi Kekerasan di Sekolah dan Lingkungan Sekitar Anak/Tim Yayasan Semai Jiwa Amini. Jakarta: PT Grasindo, anggota IKAPI

Rahardjo, Susilo \& Gudnanto. (2011). Pemahaman Individu Teknik Non Tes. Kudus: Nora Media Enterprise 